\title{
(TAX) LAW \& ECONOMICS: LIMITES CONCEITUAIS
}

\author{
(TAX) LAW \& ECONOMICS: CONCEPTUAL LIMITS
}

Brenno Birckholz da Silva*

\begin{abstract}
Resumo:
Embora profusa a literatura consagrada ao estudo correlacional entre direito e economia, divisa-se divergência teórico-conceitual significativa entre a doutrina tradicional de "Law \& Economics", e a doutrina específica de "Tax Law \& Economics". Tais prismas distintos de abordagem operam (e decorrem) tanto do ferramental analítico-teórico, como também guardam relação com o impacto correspectivo no desenho de seus sistemas regulatórios in concreto. Assim é que a construção de uma teoria ótima do direito fiscal pressuporia a internalização de elementos idiossincráticos a esta subdisciplina, não estudados na perspectivapadrão de econometria aplicada ao direito ("Law \& Economics"). Nessa quadra, destacamos como pontos únicos a este domínio do conhecimento: a) sua incapacidade dissuasória, à medida que os contribuintes sempre poderão responder à curva de taxação excessiva/mitigada modulando seu comportamento pessoal: trabalhando mais/menos, economizando mais/menos, comprando ou vendendo mais/menos; b) o particular (e complexo) problema de redistribuição, idiossincrático à cadeira de Tax Law \& Economics: enquanto políticas tradicionais de "Direito e Economia" priorizam o princípio puro de maximização de eficiência, uma política tributária ótima deve mostrar-se - ao mesmo tempo - eficiente e harmônica à capacidade contributiva e à racionalidade distributiva dos recursos na sociedade; e por fim; c) a própria discrepância entre real e ideal: conquanto plausível a estudos comuns de Direito e Economia realizar uma aproximação entre o sistema ideal e parcelas do sistema encontrado na prática, tal conexão é profundamente divergente em políticas tributárias ótimas. A consequência desta indefinição conceitual é nítida: sem um marco aproximativo mínimo, teorias podem (como fazem) livremente especular: seria a melhor política taxar (ou não) ganhos de capitais, e em alíquotas maiores (ou menores) que as atuais? A tributação da renda corporativa deveria ser aumentada (ou reduzida)? A adoção da tributação em bases territoriais (e/ou universais) deveria ser preferida (ou preterida)? Tais questões não são resolvidas pela interpretação legal típica empreendida por juristas puro-sangue; mas ao mesmo tempo também não se desatam simplesmente pelo postulado puro da maximização de eficiência econômica. A partir da correta apreensão conceitual de um estudo no âmbito de "Tax Law \& Economics", procuramos esmiuçar como prospectar abordagens vocacionadas à inflexão de um ponto ótimo de fiscalidade, seja na seara doméstica, seja na esfera internacional.
\end{abstract}

\footnotetext{
Doutorando em Direito Privado e Ciências Criminais pela Université de Bordeaux (França). Doutorando em Direito Econômico, Financeiro e Tributário pela Universidade de São Paulo (USP). Mestre em Direito e Gestão do Patrimônio Privado pela Université de Bordeaux (França), diploma reconhecido e revalidado pela Universidade Federal de Santa Catarina (UFSC). Bacharel em Direito pela Universidade de São Paulo (USP).
} 
Palavras-chave: Tax Law \& Economics. Direito Tributário Internacional. Teoria dos jogos. Política tributária e desenvolvimento econômico.

\begin{abstract}
:
Although the literature devoted to the correlational study of Law and Economics abounds, there is significant theoretical-conceptual divergence between the traditional Law \& Economics doctrine and the specific Tax Law \& Economics doctrine. Such distinct approach operates (and derives) from both its analyticaltheoretical tools and also relates to the corresponding impact on the design of the concrete regulatory systems. Thus, the construction of an optimal theory of Fiscal Law presupposes the internalization of idiosyncratic elements to this subdiscipline, not studied in the standard perspective of law-applied econometrics ("Law \& Economics"). To this extent, we highlight as unique points to this domain of knowledge: a) its dissuasive inability, as taxpayers can always respond to the excessive/mitigated tax curve by modulating their personal behavior: working more/ less, saving more/less, buying or selling more/less; b) the particular (and complex) redistribution problem, idiosyncratic to the domain of Tax Law \& Economics: while traditional "Law and Economics" policies prioritizes the pure principle of maximizing efficiency, an optimal tax policy must be both efficient and harmonious to the contributory capacity and the distributive rationality of resources in society; and finally (c) the very discrepancy between real and ideal: while it is plausible for ordinary studies of Law and Economics to bring an approximation between the ideal system and portions of the system found in practice, such a connection is profoundly divergent in optimal tax policies. The consequence of this conceptual blurring is clear: without a minimum approximate framework, theories can (as they do) freely speculate: is it the best policy to tax (or not) capital gains, and at higher (or lower) rates than current ones? Should corporate income taxation be increased (or reduced)? Should the adoption of taxation on territorial (and/or universal) bases be preferred (or deprecated)? Such questions are not resolved by the typical legal interpretation undertaken by thoroughbred jurists; but at the same time they are not simply unbound by the pure postulate of maximizing economic efficiency. Based on the correct conceptual apprehension of the study in the field of Tax Law \& Economics, we seek to investigate how to prospect approaches aimed at inflecting an optimal tax point, either at domestic level or internationally.
\end{abstract}

Keywords: Tax Law \& Economics. International Tax Law. Game Theory. Tax Policy and Economic Development.

1. (Tax) Law \& Economics : limites conceituais

É extensa a literatura correlacional estudando os efeitos entre direito e economia. ${ }^{1}$ Há divergência substancial, no entanto, entre a doutrina tradicional de "Law

Cf. Coase (1937); Salama (2008); Hansmann (1983); Geest (1996); Posner (1988); Posner (2003); Kirat (2012) e Ulen (2003). 
\& Economics", e a doutrina específica de "Tax Law \& Economics", ${ }^{2}$ tanto em termos de seu ferramental analítico-teórico, como em relação a seu impacto no desenho de sistemas regulatórios in concreto. ${ }^{3}$

A tarefa de esboçar um sistema de tributação ótimo seria intrinsecamente mais complexa, quando comparada ao desenho de sistemas Pareto eficientes de outras áreas do $\operatorname{Direito}^{4}$ (v.g., o direito concorrencial e anti-trust, o direito corporativo, as regulações da atividade atuarial e do mercado de seguros, o direito ambiental), por três razões primaciais: ${ }^{5}$

a) "a incapacidade dissuasória”: a resposta de contribuintes à tributação seria ineficiente, porque estruturada em uma transferência compulsória não consensual de recursos 6 (a exemplo do "furto", do "insider trading" e dos

\footnotetext{
Cf. Raskolnikov (2013).

Cf. Raskolnikov (2013, p. 525).
}

$4 \quad$ Uma das premissas básicas da análise de law and economics nas modelizações tradicionais seria a assertiva de que custos privados seriam também custos sociais, e benefícios privados seriam da mesma forma também benefícios sociais. Dito de outro modo, quando os agentes econômicos particulares são instados a internalizar todos os custos e benefícios na tomada de decisão, o ótimo privado passa a equiparar-se ao ótimo público, já que indivíduos racionais agindo conforme seus interesses puramente egoísticos estarão - inevitavelmente - maximizando [também] o bem-estar social como um todo. Tal identidade, no entanto, não coexiste em transferências compulsórias e não intencionais de recursos, a exemplo dos furtos e do pagamento de impostos. Nestes últimos, tomando-se por exemplo uma operação de "furto" comum, haverá - do ponto de vista da sociedade - mera transferência de recursos (ganho econômico ao ladrão, perda econômica à vítima), sem geração de benefícios ou perdas sociais, já que os ganhos e perdas serão absolutamente equivalentes entre si. A conexão de um "furto" com o direito tributário, embora aparentemente distante, é igualmente óbvia: contribuintes em práticas evasivas "furtam” a administração pública, ou no limiar, todos os contribuintes pagantes. A redução da carga tributária efetiva por intermédio de estruturas agressivas de planejamento implica transferência de recursos da sociedade ao contribuinte evasivo, e tal transferência também gera perdas sociais (equivalentes à soma dos custos de transação implicados nas condutas evasiva e translativa, conjuntamente consideradas). Há custos de transação em ambos os polos (a estrutura de pessoal mobilizada em torno de planejamentos contábeis, legais e administrativos vs. a infraestrutura de procuradores, auditores e fiscais), i.e., tanto na evasão como na correspectiva contenção. Em ambos os casos, igualmente, nenhuma atividade social útil está sendo desenvolvida. A consideração de utilidade prescinde pontualmente aqui de considerações sobre a legalidade ou ilegalidade da interposição das estruturas de planejamento tributário; antes, fixamo-nos (nesta análise tópica em específico) estritamente sob o ângulo de sua eficiência social. Cf. Kopczuk (2005, p. 12) e Coase (1937).

5 Cf. Raskolnikov (2013, p. 526).

6 Em um regime de transferência compulsória de recursos, há ineficiência mesmo se o sistema for isento de externalidades negativas. Tais transferências (e.g., um “furto”) podem (e são) desestimuladas in concreto, total ou parcialmente, não sem incorrer em dado custo (social, econômico, financeiro, de fiscalização, etc.). Nesta medida, um regime legal "ótimo" endereçado a transferências não consensuais espelharia o trade-off entre os maiores benefícios advindos do compliance com a norma, comparados aos custos de seu enforcement. Raskolnikov teoriza que, em princípio, quase todas as transferências compulsórias poderiam ser integralmente "controladas"; a contrario senso, porém, respostas ineficientes [de contribuintes] a políticas tributárias não poderiam ser "integralmente” contidas, tampouco “a qualquer custo”. Mesmo que regras antielusão pudessem eficazmente eliminar todos os tax shelters, os contribuintes sempre poderiam responder à curva de taxação excessiva modulando seu comportamento pessoal: trabalhando menos, economizando menos, comprando ou vendendo menos, etc. Não há regra de Direito capaz de alterar este 
“preços planificados”), além de geradora de externalidades negativas;

b) "o problema redistributivo": derivação da ratio anterior, a redistribuição é particularmente complexa (e idiossincrática) em Tax Law \& Economics. Enquanto políticas tradicionais de "Direito e Economia" priorizam o princípio puro de maximização de eficiência, uma política tributária ótima deve mostrar-se - ao mesmo tempo - eficiente e harmônica à capacidade contributiva e à racionalidade distributiva dos recursos na sociedade ${ }^{7}$

c) "a discrepância entre real e ideal": conquanto plausível a estudos comuns de Direito e Economia realizar uma aproximação entre o sistema ideal e parcelas do sistema encontrado na prática, tal conexão é profundamente divergente em políticas tributárias ótimas. A consequência desta indefinição conceitual é nítida: sem um marco aproximativo mínimo, teorias podem (como fazem) livremente especular: seria a melhor política taxar (ou não) ganhos de capitais, e em alíquotas maiores (ou menores) que as atuais? A tributação da renda corporativa deveria ser aumentada (ou reduzida)?

fato, e as consequências sociais da deflação/contração econômicas poderiam ser tão devastadoras quanto os mais perniciosos e agressivos planejamentos tributários encetados. Este problema - que o autor denomina "incapacidade dissuasória" ("undeterrability problem”) - poderia ser contornado, v.g., desvinculando a tributação do comportamento do agente econômico. O Professor da Universidade de Columbia afirma assim que uma taxa de montante pré-fixado e invariável ("lump-sum tax"), embora conhecida de longa data por economistas e facilmente administrável em teoria, teria pouco apelo prático em função das consequências à distributividade de impostos e ao princípio da capacidade contributiva. O problema resta sem solução. Cf. Raskolnikov (2013).

7 Dada sua natural antagonia, parece-nos prima facie e por princípio impossível resolvê-los ambos ao mesmo tempo. Uma teoria tributária global ótima contrabalançaria os benefícios da redistribuição de recursos com os custos inevitáveis das distorções induzidas pela introdução de tributos no mercado livre, maximizando coeteris paribus o bem-estar social universal. Uma tal "teoria de tudo" é - sem sombra de dúvidas - a "menina dos olhos de ouro" da macroeconomia pública (no original em inglês, "crown jewel of public economics”). Ela é, em igual medida, bastante distinta da análise-padrão de externalidades ou falhas de mercado empreendidas em estudos tradicionais de "Direito e Economia", estes últimos ferramentas úteis e conceitualmente práticas à maximização do bem-estar social a partir da racionalização do comportamento individual dos agentes econômicos. Uma teoria tributária ótima, no entanto, adicionalmente a tais premissas, não se desenvolve senão após introjetar uma terceira variável: a capacidade contributiva (ou qualquer outro atributo substitutivo) para dimensionamento da base redistributiva do imposto, em seguida teorizando-se acerca da extensão ótima de redistribuição, determinação de seu custo e modus de harmonização teórica (com outros princípios do sistema tributário) e prática (pelo Fisco em face dos jurisdicionados). Cada uma dessas decisões é contaminada por julgamentos axiológicos (de valor), incertezas empíricas, e/ou ambos, ínsitas a cada país e jurisdição. O resultado desta complexidade imensa é inconteste (e consabido): os sistemas tributários nacionais hodiernos estão ainda longe de uma construção ótima, tal qual a idealizada nos livros. Nas palavras de Alex Raskolnikov, in verbis. "This gap between the real and the ideal is at the heart of the third problem of tax law and economics - the baseline problem". Em tradução livre: "Esta discrepância entre real e ideal está no coração de um terceiro problema de "Tax Law \& Economics": o problema de 'linha de base'(i.e., a absoluta falta de correspondência entre o plano teórico-ideal e o plano prático-vigente)’. Cf. Raskolnikov (2013, p. 526). 
A adoção da tributação em bases territoriais (e/ou universais) deveria ser preferida (ou preterida)? Tais questões não são resolvidas pela interpretação legal típica empreendida por juristas puro-sangue; mas ao mesmo tempo também não se desatam simplesmente pelo postulado puro da maximização de eficiência econômica. ${ }^{8}$

\section{A "Panaceia Universal": por que a resposta ótima à tributação é "nenhuma resposta"}

Prima facie, parece-nos claro que os problemas enfrentados pela doutrina tradicional de Law \& Economics divergem substancialmente daqueles afetos à subdisciplina de Tax Law \& Economics. Corolário lógico, também o endereçamento das soluções propostas por cada qual das vertentes ${ }^{9}$ aferra-se a premissas e propostas igualmente particulares. ${ }^{10}$

Uma abordagem standard de Law \& Economics mostra-se apropriada a atividades per si socialmente desejáveis, cujos condicionantes próprios a cada cultura e sociedade modularão apenas o quantum, isto é, a intensidade de sua prática. ${ }^{11}$

A título ilustrativo, tomemos dois exemplos práticos divisados pela doutrina: conduzir veículos e manufaturar produtos na indústria. Ambos são sabidamente geradores de problemas sociais e externalidades negativas: aquele, por causar acidentes; esta, por poluir o meio ambiente. A despeito disso, não conseguiríamos sustentar razoavelmente um incremento de bem-estar social geral, ${ }^{12}$ caso pudéssemos reduzir a zero acidentes e

\footnotetext{
8 A elas, parece-nos em adendo, o endereçamento correto da análise interdisciplinar entre o direito tributário e a econometria estatística é ferramental muito útil (ainda que não suficiente à resolução integral de problemas de per si). A aceitação das limitações de Taw Law \& Economics traz também redefinições à agenda de debates de políticas tributárias fundamentais, e mais importante, permite - a partir de estimações e estudos empíricos conexos à realidade vigente - melhor dimensionar políticas públicas e seus elaboradores com informação útil ao desenvolvimento de modelizações - muito mais afeitas à realidade do que fórmulas especulativas ideais. Segundo o Professor Alex Raskolnikov, há que se reconhecer as vantagens comparativas exclusivas de tributaristas com domínio das ciências econômicas, e de economistas de finanças públicas com domínio do direito tributário. Cf. Raskolnikov (2013).

9 A conjunção das três premissas explicitadas no item anterior "1. (Tax) Law \& Economics: limites conceituais" explicitariam, a um só tempo: a) um grande desafio aos elaboradores de políticas públicas tributárias, e b) (evidentemente) os limites conceituais da subdisciplina de Taw Law \& Economics. Cf. Raskolnikov (2013, p. 545).

10 Seria esta a razão pela qual o approach tradicional de maximização da eficiência social a partir da aglutinação de comportamentos egoísticos isolados - nítida abordagem law and economics - não encontra ressonância e aderência diretas na formulação de políticas públicas tributárias ótimas (tax law and economics). Cf. Raskolnikov (2013).

11 Cf. Raskolnikov (2013).

12 Ao menos não no atual estado da arte da técnica da indústria manufatureira e automotiva.
} 
poluição por meio da proibição integral de qualquer condução de veículos, e de qualquer manufatura.

Ora, cuida-se ambos - carros e indústrias - de atividades socialmente desejadas em algum nível, apesar de seus malefícios. Aqui a discrepância cultural será tópica, e limitar-se-á basicamente ao quantum (a intensidade) desejada (ou não). Em outros termos, porque socialmente desejadas, tais atividades serão objeto de regulações normativas específicas, endereçadas a incentivar e premiar, ou reprimir e coibir, comportamentos, ${ }^{13}$ na extensão da variável institucional e cultural de cada país.

Diferente, no entanto, será com a tributação. Como já demonstrado cientificamente, ${ }^{14}$ a introdução de impostos reduz a quantidade de bens/serviços disponível, à luz do próprio axioma de oferta e demanda. Gera-se destarte uma ineficiência econômica ("deadweight-loss") 15 correspondente ao volume de transações que poderiam ter sido feitas em maximização dos excedentes de ambos os polos consumidor e produtor, mas que não o foram pela diminuição da oferta/demanda gerada pelo aumento de preços marginal. ${ }^{16}$

Em síntese, a introdução de um tributo modula o comportamento dos agentes econômicos, ${ }^{17}$ de modo que menor quantidade do bem é comprada ( "consumidores consomem menos do que seria eficiente”), e menor quantidade do bem é vendida ("produtores produzem menos do que seria eficiente"). Estas perdas constituem o excesso de carga ("excess of burden") 18 do imposto, i.e., um custo social que excede qualquer benefício gerado por receitas tributárias arrecadadas. ${ }^{19}$ Graficamente, essa discrepância é representada pelo que a literatura econômica convencionou denominar "triângulo de Harberger": ${ }^{20}$

\footnotetext{
13 Cf. Bobbio (2007, p. 324-325; 1980, p. 1-27).

14 Cf. Krugman (2015), em especial o capítulo 5: "Controle de preços e cotas: intervenção nos mercados"; Krugman (2007, p. 428 et seq.); Hines, 1998, p. 1-38; Birckholz da Silva (2020).

15 Cf. O’Reilly $(2010 ; 2008)$.

16 O aumento marginal do preço final é decorrência direta do "sobrepreço" tributário.

17 Cf. Krugman (2007, p. 428 et seq.).

18 Cf. Krugman (2007, p. 428 et seq.).

19 Cf. Raskolnikov (2013, p. 536).

20 No gráfico desenhado abaixo, o triângulo é representado hachurado em amarelo. Cf. Hines (1999).
} 
MERCADO EM EQUILÍBRIO

ANTES DE TRIBUTOS

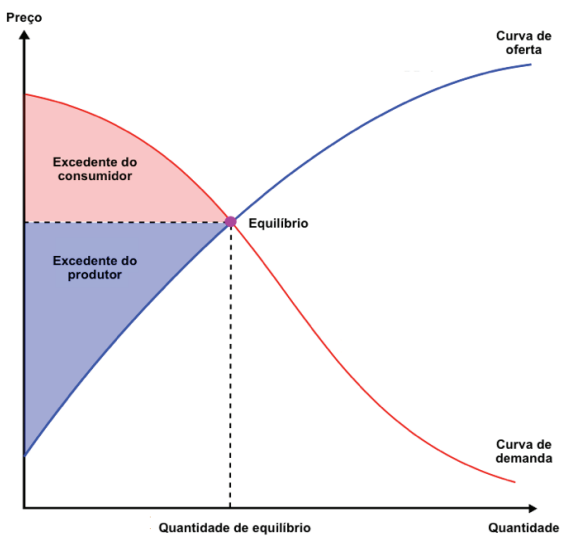

MERCADO EM EQUILIBRIO

APÓS TRIBUTOS

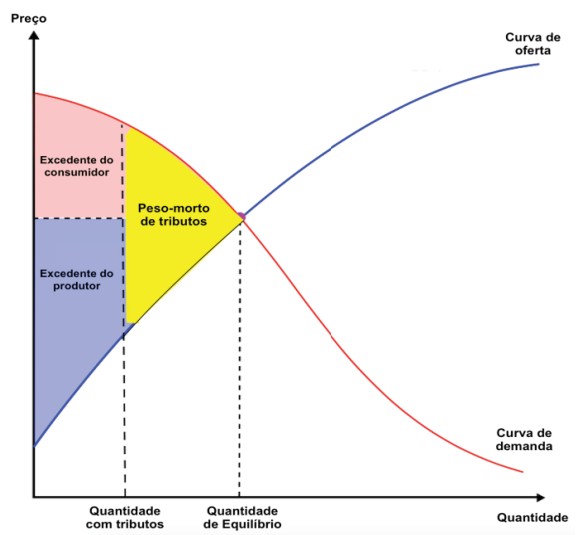

Á área em amarelo representa os excedentes (do consumidor e do produtor) "perdidos" em função da introdução de um tributo. Este "diferencial" distorsivo constitui justamente o montante incapaz ${ }^{21}$ de ser recuperado pela arrecadação tributária.

Nessa medida, embora a área do triângulo amarelo (representativa das perdas econômicas geradas pelo efeito-distorsivo da tributação) seja variável, ${ }^{22}$ a revisão de literatura econômica ${ }^{23}$ demonstra que independentemente do mercado, da sociedade e da alíquota tributária, qualquer tributação proporcional às unidades econômicas transacionadas implicará necessariamente a existência de um triângulo de Harberger, ${ }^{24}$ ou em termos diretos, qualquer tributação proporcional às unidades econômicas trará em seu bojo um deadweight-loss.

Corolário lógico, a resposta "ótima" à tributação $0^{25}$ será via de regra "nenhuma resposta", ${ }^{26}$ já que a medida "ótima" de distorção do comportamento dos

21 Em termos matemáticos, ao tentar apropriar-se de parcela dos excedentes de produtores e consumidores [ "Exc ${ }_{P+C}$ "] em transações econômicas equilibradas, um Estado consegue arrecadar receitas [ "Trib"] porém de modo tal que, sempre e invariavelmente, $\left[\right.$ Trib $\left.<E x c_{P+C}\right]$.

22 A variabilidade da área (e portanto da extensão maior ou menor das perdas econômicas por peso-morto tributário) é afeta à elasticidade da demanda e oferta de consumidores e produtores.

${ }^{23}$ Cf. O’Reilly (2010, p. 19), Krugman e Wells (2015, p. 428 et seq.).

${ }^{24}$ Cf. Hines (1999).

25 Tomamos por premissa que a tributação ora considerada é aquela que se apropria de unidades econômicas proporcionalmente à sua produção/consumo. Embora relevante do ponto de vista teórica, a quase inexistência prática de tributos em tipologia "lump-sum tax" faz com que não nos dediquemos a eles com especial aprofundamento neste trabalho. Para uma análise de sua perspectiva ótima, cf. Mankiw, Weinzierl e Yagan (2009).

26 Em teoria, uma análise behaviorista ideal seria aquela cujo comportamento tivesse zero-distorsão em face 
agentes econômicos provocado pela tributação é “zero". ${ }^{27}$ Com isto, quer-se dizer a um só tempo:

a) a racionalidade-padrão da doutrina de Law \& Economics, orientada a determinar o montante ótimo ${ }^{28}$ de dada atividade ao estudar sua correlação “custo/benefício”, não teria utilidade prática à subdisciplina de Tax Law \& Economics, à medida que o ponto ótimo de inserção de tributos em uma economia de livre mercado - sob análise e metodologia estritamente econômico-racional - é necessariamente zero;

b) o excesso de carga ("excess of burden") decorrente de ineficiências estruturais ("peso-morto") faria da introdução de tributos proporcionais às unidades econômicas produzidas uma atividade per si socialmente indesejada, à medida que - independentemente do mercado, da sociedade e da alíquota tributada - sua correlação "custo/beneficio" será sempre negativa, ou seja: $\{[$ custos] $>$ [beneficios $]\}$;

c) não obstante, tratar tal abordagem ${ }^{29}$ como "panaceia universal" seria não apenas simplista e reducionista, como ignoraria também as sistemáticas de tributação existentes hoje $\mathrm{e}^{30}$ na totalidade das jurisdições nacionais, e via de regra, também na integralidade dos sistemas de tributação praticados hodiernamente;

d) eis porque, dentro dos limites factuais "do possível”, caberá à

da introdução de tributos. Esta possibilidade, como já demonstrado alhures, é utópica e matematicamente impossível para tributos proporcionais às unidades econômicas produzidas/consumidas. Cf. Raskolnikov (2013. p. 536).

27 Cf. Raskolnikov (2013, p. 536).

28 Por pressuposição lógico-matemática, um tal montante em Law \& Economics será necessariamente positivo, isto é, diferente (e superior) a "zero".

29 Cf. Raskolnikov (2013. p. 536).

30 Cumpre-nos ressalvar a existência tópica de um tipo particular de tributo, não tratado neste trabalho. Como salientado pelo economista inglês e discípulo de Alfred Marshall, Arthur Cecil Pigou, se determinada atividade ou transação é modulável em níveis ótimos a partir de regras de responsabilização civil e sanções pecuniárias (multas), então ela também poderia ser regulada mediante introdução de taxas de natureza jurídica tributária, destinadas a corrigir as externalidades negativas ou positivas geradas por tais atividades. Tais tributos - contrabalanço à correção de externalidades (v.g., custos sociais gerados pela poluição, ou contribuições de melhoria por ganho de valor no entorno de obras vultosas) - foram denominados "impostos pigouvianos". Tal categoria conceitual aceitaria os modelos e métodos tradicionalmente empregados em Law \& Economics, já que sua atuação se dá dentro de um objetivo preliminar específico e pontual, de incentivar/desincentivar condutas tópicas geradoras de externalidades positivas/negativas (per si socialmente desejadas/indesejadas). O objetivo primacial de tais tributos peculiares, portanto, não é arrecadar receitas, e deles não nos ocupamos no curso deste artigo por limitações de escala e escopo. Para uma análise aprofundada dos efeitos extraeconômicos marginais de atividades produtivas, cf. Pigou (1932, p. 192-203). 
interdisciplinaridade Tax Law \& Economics introduzir as variáveis institucionais idiossincráticas a cada jurisdição nos cálculos de "custo/ beneficio" econométricos, extraindo desta correlação qual o binômio que otimiza benefícios e minimiza custos, ${ }^{31}$ ciente $a b$ initio de que, para todas as hipóteses assumidas, tal curva não tem como ser Pareto eficiente. ${ }^{32}$

\section{3. "Irredeemably inefficient acts": quando a ineficiência está na essência}

Ao conjunto de transferências não consensuais ${ }^{33}$ - atos ineficientes por essência ${ }^{34}$ - a doutrina econômica ${ }^{35}$ deu o nomen "atos irremediavelmente ineficientes", ou simplesmente "atos irremediáveis". À tributação - um dentre os distintos atos irremediáveis, e por essência economicamente ineficientes - acresce ainda a peculiar condição de incapacidade dissuasória total. ${ }^{36}$

Isto significa que, mesmo que todos os mecanismos hoje existentes de planejamento fiscal agressivo pudessem ser previstos e em seguida proibidos, e portanto mesmo que todos os tax shelters fossem eliminados do globo, ainda restaria uma alternativa peculiar a contribuintes para responder ao incremento da carga tributária: simplesmente não incorrer no fato gerador. ${ }^{37}$

31 Dentre os custos associados à tributação, destacam-se: a manutenção do aparato fiscalizador e da infraestrutura de procuradores, auditores, fiscais e insumos judiciais e extrajudiciais; os riscos de má-identificação de erros simples/honestos como efetivas manobras fraudulentas de evasão/elusão fiscal ( "mislabel costs"); os custos associados à resistência natural de contribuintes evasores-habituais, ao readaptar suas estruturas e mecanismos às novas previsões legais e assim contornar a incidência tributária ("resistance costs"). Cf. Raskolnikov (2013, p. 537).

32 Assim, a única maneira de uma taxa ou tributo qualquer ser Pareto eficiente seria quando o contribuinte (e portanto o mercado livre) não tivesse qualquer reação - positiva ou negativa - diante de sua existência. Cf. Raskolnikov (2013).

33 São inseridas em tal subconjunto, v.g.: a formação de cartéis; a precificação planificada de insumos e bens/ serviços; os estelionatos; o estímulo à compra e venda de ações por corretores, apenas para gerar novas comissões no volume de operações transacionadas ( "churning"); a manipulação fraudulenta de licitações; o insider trading; a manipulação de mercados mobiliários; o peculato; os furtos e subtrações equiparadas; a retroação ("pré-datação") de opções; entre outros. Quase todos constituem condutas ilícitas na grande maioria dos sistemas jurídicos, o que denotaria de per si a avaliação pejorativa que os direitos positivos fazem quanto a tais condutas. Cf. Raskolnikov (2013).

34 A ratio econômica da ineficiência ínsita a cada qual está na correlação inarredável: $\{[$ custos $]>[$ beneficios $]\}$, isto é, em uma estatística em que o custo marginal social ou individual da prática de dado ato ou transação sempre e necessariamente supera o conjunto de benefícios marginais sociais ou individuais correspectivos.

35 Cf. Raskolnikov (2013).

36 Cf. Raskolnikov (2013).

37 Com isto dizemos não incorrer licitamente no fato gerador, ou de modo mais direto, não praticar a operação ensejadora da obrigação tributária stricto senso. Eis porque a modulação ineficiente da curva tributária poderá implicar a inércia econômica total do sujeito passivo. Cf. Raskolnikov (2013). 
No cenário utópico (tax planning $=0$ ), sempre que o custo privado de $n \tilde{a} o$ realizar dada transação ${ }^{38}$ for inferior $^{39}$ ao custo privado de pagar os tributos respectivos, o resultado será pura e simplesmente a inexistência da transação, e ipso facto, a inexistência de qualquer arrecadação aos cofres públicos. ${ }^{40}$

A constatação é óbvia, e remete à curva de Laffer (2004, p. 1-3): a partir de dada alíquota ad valorem, o benefício marginal de uma nova unidade econômica (produzida ou consumida) passa a ser inferior ${ }^{41}$ ao seu custo marginal (a tributação sobre referida unidade produzida ou consumida): assim, trabalha-se menos, economiza-se menos, compra-se/vende-se menos. ${ }^{42}$

O fato de a tributação constituir atividade "ineficiente por essência" ao menos no plano econômico - sempre intrigou a doutrina econômica, ${ }^{43}$ motivando profissionais da macroeconomia e finanças públicas a desenvolver teorias ${ }^{44}$ endereçadas a harmonizar a um só tempo problemas aparentemente inconciliáveis entre si: a "incapacidade dissuasória" e o "problema redistributivo". De uma delas ${ }^{45}$ cuidamos especialmente a seguir.

4. A teoria do "ponto ótimo" de tributação da renda

A teorização de James Mirrlees (1971, p. 175-208) ${ }^{46}$ inaugura a especulação de um ponto ótimo de tributação da renda, de modo aprofundado e referendado pela doutrina econômica. ${ }^{47} \mathrm{~A}$ despeito de suas inúmeras limitações, ${ }^{48}$ fundamentalmente um sistema

38 Cuida-se do fato jurígeno da relação jurídico-tributária. Cf. Carvalho (2007, p. 146).

39 Evidentemente, trata-se de uma visão e percepção pessoal a cada agente econômico, afeta portanto a grupamentos culturais e valores específicos a dado povo e nação. Cf. Reale (2002, p. 557).

40 Nesse caso, ou o contribuinte simplesmente desiste da operação in concreto, ou a fará de modo sub-reptício e/ou não declarado. Em todos os casos, dessume-se que o acréscimo de complexidade e custo tributário diminui a atratividade marginal da operação, até o momento em que o agente econômico conclui - em face dos incômodos e dos custos de oportunidade e de transação envolvidos - que a operação "deixou de valer a pena".

41 Como dito em nota de rodapé anterior, a percepção de superioridade ou inferioridade é pessoal a cada agente, e sujeita-se destarte a valores culturais próprios a dado povo e nação. Cf. Reale (2002, p. 557).

42 Os atos de "trabalhar", "economizar" e "comprar/vender" passam a ter cada vez menor valor agregado, quando comparados ao ato inercial ("nada fazer"). Essa perda de valor nada mais é que a tradução empírica do conceito econométrico de "custo de oportunidade”. O fato de a sobretaxação incentivar a inércia e a improdutividade econômica é explicada por Laffer, em fenômeno denominado por Raskolnikov "incapacidade dissuasória” ("undeterrability problem”). Cf. Laffer (2004) e Raskolnikov (2013, p. 537).

43 Cf. Raskolnikov (2013, p. 537).

44 Para uma análise das teorias propostas por doutrinadores legais à avaliação do direito tributário em termos de eficiência econômica, cf. por outros: O’Reilly (2010).

45 Cf. Mirrlees (1971).

46 Cf. Mirrlees (1971).

47 Cf. Mankiw, Weinzierl e Yagan (2009).

48 A fim de teorizar um modelo ótimo de tributação, capaz de harmonizar as perspectivas dúplices de 
ótimo de tributação seria progressivo, não linear e incidente sobre a renda produzida (i.e., sobre a força de trabalho), e não sobre a renda poupada (i.e., o capital). A teoria ótima de Mirrlees (1971, p. 175) endereça-se ao desafio redistributivo e à inevitabilidade do peso-morto tributário, focando destarte a otimização ${ }^{49}$ do trade-off entre redistribuição e distorção.

Em sua configuração básica, a redistribuição seria um valor desejado à medida que a utilidade marginal da renda seria decrescente. ${ }^{50}$ Redistribuir de contribuintes com maior capacidade contributiva àqueles de menor poder aquisitivo, consequentemente, aumentaria o bem-estar social, já que os ganhos de utilidade destes superariam as perdas de utilidade daqueles. ${ }^{51}$ Nada obstante, fosse esse o único considerando em jogo, uma teoria de maximização da utilidade social reclamaria completa igualdade de rendas, quando consabidamente tal fato não sucede na prática, em função da distorção provocada pela própria redistribuição. ${ }^{52}$

Em vista desses desafios, não é por acaso que, embora existente literatura jurídica dedicada ao aperfeiçoamento dos sistemas tributários atuais e suas respectivas

redistribuição e de incapacidade dissuasória, Mirrlees implementou simplificações conceituais, criticadas por autores subsequentes. Dentre elas está a assunção de que indivíduos são presumidos idênticos em todos os seus aspectos e preferências, exceto por sua renda e capacidade de geração de renda através da força de trabalho ("earning ability"). Assim, desconsideram-se preferências de consumo ou gostos individuais (v.g., a possibilidade de dado agente econômico dispor de largas quantias economizadas, mas preferir levar um estilo de vida frugal). Uma segunda pressuposição considera que a utilidade de dado produto ou serviço seria decomponível em uma divisão binária entre "consumo" e "lazer", desconsiderando, no entanto, a existência de substitutos ou complementos a um e a outro e/ou entre si. Por suas assunções consideradas ideais e dissociadas da realidade, o argumento de superioridade do modelo é alvo de críticas em igual medida. Ainda assim, seria “o melhor que a macroeconomia pública teria a oferecer”. Cf. Mirrlees (1971) e Raskolnikov (2013, p. 537).

49 Ao focalizar um ponto de “otimização” entre dois eixos matematicamente inconciliáveis entre si, dá-se-lhe a nomenclatura "ponto ótimo”, não sem ressalvar que referido ponto de equilíbrio por definição conceitual estará fora da curva do ótimo Pareto eficiente. Para os fins e recortes metodológicos deste trabalho, introjetam-se variáveis institucionais de cada jurisdição para [tentar] extrair relações de "custo/beneficio" econométricas. Ao maximizar benefícios e minimizar custos, nosso escopo grosso modo segue as bases fundacionais da modelização inaugural de Mirrlees. Eis porque - guardadas as limitações de escopo e escala da presente Tese - denominamo-la "ponto ótimo de tributação internacional” a partir de um estudo de “custo/beneficio tributário”. Cf. Mirrlees (1971).

50 Cf. Raskolnikov (2013, p. 547).

51 Cf. Kaplow (1996).

52 Ao taxar de modo progressivo (portanto com alíquotas maiores a renda dos contribuintes mais ricos), haveria indução distorcida na escolha entre "trabalho" e "lazer", privilegiando-se (presumidamente) a escolha racional pelo lazer. O peso-morto tributário daí resultante acabaria por "compensar" os benefícios redistributivos. Isto faria com que um sistema tributário "ótimo” fosse basicamente constituído: a) por base uma renda mínima fixa (v.g., um salário universal, garantido a todo cidadão) e b) uma agenda de alíquotas marginais regressivas (ao invés de progressivas). A larga maioria dos sistemas tributários hoje vigentes, no entanto, apresenta alíquotas progressivas de tributação da renda, i.e., à medida que a renda aumenta, maiores também serão as alíquotas aplicadas. Cf. Bankman (1987). 
sanções sob a ótica econômica, pouca (quase nenhuma) ${ }^{53}$ é fundada em um "regime ótimo”, e mesmo quarenta anos após a teoria inaugural de Mirrlees (1971, p. 175), ${ }^{54}$ não há consenso, seja quanto ao quadro-arquétipo de melhor redistribuição de renda em dada sociedade, ${ }^{55}$ seja quanto à progressividade, regressividade e/ou proporcionalidade do sistema. ${ }^{56}$ Trata-se essencialmente de discussão que desborda ${ }^{57}$ dos limites conceituais de Tax Law \& Economics, para tangenciar o campo da Filosofia Moral. ${ }^{58}$

53 David Weisbach e Louis Kaplow, inter alia, dedicaram-se ao diálogo macroeconomia-direito tributário em face de particularidades concretas de cada jurisdição. O primeiro, por exemplo, enfoca a maximização de bem-estar social a partir do custo marginal de eficiência ( "marginal efficiency cost of funds") e a elasticidade das curvas tributárias, concluindo que políticas públicas com o menor MECF deveriam ser privilegiadas, à medida que permitiriam aumentar receitas com o menor custo social. O segundo, por sua vez, reputa necessário refletir na maximização do bem-estar social as preferências distributivas de dada sociedade estudada. Assim, para este último, tanto maior a complexidade e precisão do sistema tributário (espelhando as idiossincrasias de dado povo), e mais próximos estaríamos do objetivo último de maximização desse bem-estar. Uma análise do custo dessa complexidade é empreendida em seguida, para aferir se os ganhos incrementais de bem-estar social são ou não pareados com os custos da maior complexidade do sistema. Outras análises de custos de compliance e enforcement realizam-se pari passu. Para uma visão da tentativa de conectar a macroeconomia pública à otimização de normas tributárias existentes nos sistemas tributários concretos do mundo real, cf. por outros: Kaplow (1996); Weisbach (2002); Slemrod (1990) e Slemrod (2004).

54 Cf. Mirrlees (1971).

55 Cf. Raskolnikov (2013, p. 564).

56 O desenvolvimento teórico de uma função otimizadora (a exemplo da perspectiva de maximização de bemestar social, ao escolher v.g. o critério redistributivo lastreado no nível de renda/salário) ainda assim não resolve o problema in concreto. Resta pendente de solução o desenho deste sistema distributivo em dada sociedade, e consideradas as peculiaridades histórico-culturais de cada grupamento de indivíduos, esta definição está longe de pré-formatada: cuida-se de um processo de "adivinhação empírica" (no original em inglês, "empirical guess"). Cf. Raskolnikov (2013, p. 564).

57 Não há respostas óbvias/prontas a qual deveria ser a base redistributiva, $v . g$. se lastreada na habilidade pessoal, na capacidade contributiva, em benefícios, sacrifícios, oportunidades potenciais, sorte, estética física, etc. Apesar de aparentemente jocosos ou desconexos alguns dos critérios, nenhum seria dotado de uma preferência econômico-racional imanente, e a matéria é muito mais afeta à julgamentos morais de filosofia política que à doutrina econômica stricto senso. Harold Groves, por exemplo, analisa as visões empreendidas por economistas de renome em distintas épocas e escolas acerca dos melhores critérios à redistribuição: Adam Smith, John Stuart Mill, John Maynard Keynes, Arthur Cecil Pigou, Nicholas Kaldor, John Hicks, entre outros. Cf. Groves (1974, p. 7 et seq.).

58 Modelizações neste sentido não são raras na doutrina. Linda Sugin afirma inexistir "[um] sistema tributário idealmente justo, dado que a justiça na tributação está entrelaçada aos efeitos de mercado, às provisões públicas de bens e serviços e às instituições políticas. Contra o pano de fundo de arranjos institucionais particulares, um tipo de imposto poderia assim ser claramente superior a outro. Em dado sistema econômico com pouca desigualdade, um estado de bem-estar robusto e instituições desenvolvidas para educação, assistência à infância e saúde, um imposto com potencial de redistribuição limitado poderia financiar adequadamente oportunidades econômicas e segurança para os cidadãos. Já uma sociedade com grande riqueza, grande desigualdade de renda e educação pública, serviços sociais e atendimento médico inadequados exigiria um sistema fiscal mais redistributivo, enquanto ferramenta de justiça econômica". Em arremate, a Professora preleciona que a justiça na tributação deveria ser contabilizável nos mesmos termos que outras instituições governamentais. Cf. por outros: Sugin (2011, p. 229 et seq.). Tradução livre deste autor. 
5. O ponto “quase-ótimo”: benefícios da análise econômica do direito tributário internacional

Sem prejuízo da análise tradicional de Tax Law \& Economics, cuja premissa teórica ótima de não taxação traz como melhor resposta tributária justamente "nenhuma resposta", ${ }^{59}$ a doutrina contemporânea tem revisitado ${ }^{60}$ assunções teóricas daquela, com o objetivo de aproximá-las da realidade prática. ${ }^{61}$

A nova agenda ${ }^{62}$ de pesquisas reexamina conclusões tradicionais ${ }^{63} \mathrm{e}$ internaliza novas (e outras) variáveis ${ }^{64}$ no cálculo das "capacidades contributivas". $\mathrm{O}$ escopo é torná-las mais afinadas à responsividade ${ }^{65}$ individual concreta dos sujeitos passivos vis-à-vis as normas tributárias. ${ }^{66}$

59 Cf. o item "2. A 'panaceia universal': por que a resposta ótima à tributação é 'nenhuma resposta"”, deste trabalho.

60 Cf. Raskolnikov (2013, p. 582).

${ }_{61}$ Conesa, Kitao e Krueger, por exemplo, desenvolveram um modelo lastreado na endogeneidade da força de trabalho e no diferencial de produtividade ao longo do ciclo de vida média expectada dos indivíduos, para concluir que um sistema tributário ótimo a longo prazo - a contrario senso da análise tradicional - taxaria fortemente o capital e concomitantemente o rendimento do trabalho, ambos em alíquotas fixas e proporcionais (i.e., nem progressivas, nem regressivas), ressalvando à tributação da força de trabalho o direito à dedutibilidade de dado piso salarial. Utilizando-se da metodologia desenvolvida, os autores "calibraram-na" valendo-se de dados macroeconométricos referentes à economia norte-americana. Os resultados obtidos sugerem que, para aquele país, a tributação da renda corporativa seria ótima em patamares de $36 \%$ (trinta e seis por cento). Já a tributação ideal sobre a força de trabalho, em uma primeira aproximação, seria pré-fixada em $23 \%$ (vinte e três por cento), com uma dedução admitida de US\$ 7.200,00 (sete mil e duzentos dólares), para um PIB per capita considerado da ordem de US\$ 42.000,00 (quarenta e dois mil dólares). A explicação de tal estrutura fiscal ótima estaria em que, idealmente, a tributação ótima do capital derivado da venda da força de trabalho seria realizada a taxas distintas, variáveis conforme a idade/ produtividade do trabalhador. Ausente tal possibilidade de tributação variável sobre o capital oriundo do trabalho (por questões práticas e/ou de aceitação social), um imposto de renda sobre o capital permitiria à Administração alcançar idêntico efeito. Cf. Conesa (2009).

${ }^{62} \mathrm{O}$ plexo de pesquisas hoje empreendidas é predominantemente um campo de estudo de economistas, e não de profissionais do Direito. Aqueles não apenas não têm, como não precisam ter, conhecimentos aprofundados das regras normativas e suas respectivas sanções. Ao mesmo tempo, a maioria dos advogados tributaristas dotados de noções sofisticadas de Economia não consegue igualar-se ao nível de modelização empírico-econométrica dos economistas de elite. Esta nova agenda de pesquisa parte do pressuposto de que um ideal utópico de "nenhuma tributação", tal qual descrito no parâmetro ótimo, é dificílimo porque impraticável in concreto, ao menos no atual estado da arte da tecnologia jurídica. Cf. Raskolnikov (2013, p. 580).

63 Dado o grau de dissociação entre o "ponto ótimo tributário" e o "ponto aceito socialmente e vigente”, as conclusões da perspectiva consolidada e tradicional de Tax Law \& Economics prefiguram-se utópicas e desconectadas.

64 Dentre elas, por exemplo, a capacidade laboral afeta à expectativa de vida média, gênero, idade concreta, compleição física, grau de instrução e rendimento escolar/acadêmico, entre outros. Cf. nota de rodapé anterior.

65 Cuida-se da mensuração empírica e quantitativa do grau de elasticidade de cada qual dos novos parâmetros escolhidos, em face da introdução de dada regra-matriz de incidência tributária.

${ }^{66}$ Cf. Raskolnikov (2013, p. 582). 
Embora sob ponto de vista puramente econômico, a curva de análise empreendida seja por definição Pareto ineficiente, um endereçamento prático da análise interdisciplinar entre o direito tributário e a econometria estatística, a partir da análise econômica do direito tributário (tax law and economics), parece-nos constituir ferramental muito útil ${ }^{67}$ (ainda que não suficiente de per si) à resolução de problemas concretos.

Compreendidos os limites de Taw Law \& Economics, também os debates de políticas tributárias fundamentais poderiam ser aprimorados, integrando-se doravante de estimações e estudos empíricos conexos à realidade vigente, cujo dimensionamento será tanto mais útil aos policymakers quanto mais afeitos à realidade estudada.

Ademais, análises econômicas remanescem fundamentais à demonstração de nexos de interdependência entre normas tributárias, microeconomia e a racionalidade econômica dos contribuintes. ${ }^{68}$ Além de melhor prever o comportamento dos players no mercado, a atual "humanização" da racionalidade ${ }^{69}$ permitiria introjetar valores emocionais/culturais sociotípicos a dado grupamento coletivo, e assim não só maximizar a certeza estatística de previsões, como associá-las ${ }^{70}$ às políticas tributárias de incremento arrecadatório geradoras dos menores ruídos econômicos possíveis. ${ }^{71}$

\section{A “teoria dos jogos" e seu impacto na cooperação multilateral internacional}

O desajuste presente de capacidades econômicas "contributiva" e "contribuída" - ou dito de outro modo, a desarmonia entre quanto é faturado, e o montante respectivo de tributos que é pago - constitui fenômeno de que coparticipam diretamente cidadãos e empresas (sujeitos passivos da relação tributária). ${ }^{72}$

Não obstante, no plano entre-nações, não são apenas as corporações (contribuintes) as únicas responsáveis pela ruína do atual sistema fiscal internacional. ${ }^{73}$ inclusive um axioma de racionalidade do sistema econômico capitalista, necessário à certas modelizações econômicas, que no limite explicaria em que grau e medida o direito tributário pode distorcer as dinâmicas do mercado, encarecendo ou barateando artificialmente o plexo de fatores produtivos, e aumentando ou diminuindo o próprio bem-estar global. Como preleciona Avi-Yonah (2000, p. 4): "Quando a carga fiscal efetiva offshore é inferior à doméstica, os contribuintes preferirão investir no exterior mesmo quando a taxa de retorno do investimento doméstico antes do desconto de tributos seja maior, diminuindo assim o bem-estar global". No original, verbis: "When the effective tax rate abroad is lower than the effective rate at home, taxpayers will prefer international investments even when the return on domestic investments is higher before taking taxes into account, thus diminishing global welfare".

73 Cf. Carbajo Vasco (2015, p. 61).
} 
Também governos e respectivas administrações tributárias têm sua parcela de culpa no grau de entropia normativa e econômica, como reflexo direto de suas práticas nacionalistas. ${ }^{74}$ Assim, a título de exemplo, o conclamado projeto BEPS somente se revelará eficaz respondendo de modo consonante aos reclamos da dinâmica econômica do século XXI - caso a estratégia de cooperação das atuais administrações tributárias nacionais seja substancialmente: a) primeiro revista, b) segundo, implementada. ${ }^{75}$

Ilustração do exposto $^{76}$ estaria no bilateralismo das relações fiscais internacionais, cuja existência conjunta e fragmentada de mais de 3.000 (três mil) instrumentos bilaterais - a grande maioria seguindo o quadro-modelo OCDE - não apenas contrapõe-se à realidade econômica multilateral vigente, como favorece o desenvolvimento de mecanismos próprios e complexos de combinação de tratados para fins de planificação fiscal.

Nessa quadra, uma das ferramentas conceituais de grande capacidade analítica em estratégias de cooperação é a teoria matemática dos jogos. Uma "teoria dos jogos" define-se como a análise matemático-formal de situações ( "jogos") envolvendo conflitos de interesses aparentemente antagônicos e irreconciliáveis. ${ }^{77}$ Como todos os interesses não podem ser atendidos ao mesmo tempo - em flerte com a natural ideia econômica de escassez ${ }^{78}$ - são desenvolvidas modelizações matemáticas descrevendo interações competitivas, cujo escopo será encontrar estratégias racionais "ótimas" ${ }^{79} \mathrm{O}$ desenlace dessas situações ( "resultado") dependerá do conjunto de estratégias adotadas individualmente por cada qual dos agentes envolvidos ("jogadores”), o que permitirá extrair correlações de cooperação ${ }^{80}$ ou antagonismo. ${ }^{81}$

De modo absolutamente simplificado, uma teoria dos jogos ("game theory”) estuda como os jogadores deveriam racionalmente jogar o jogo, i.e., qual a melhor estratégia que poderiam adotar. “Jogo”, nesta acepção, será qualquer situação de

\footnotetext{
74 A elas referimo-nos anteriormente como nítido "tax shopping”, a recrudescer as disparidades de tratamento interjurisdicional ("hybrid mismatch arrangements"). Embora legítimo o interesse em atrair investimentos para seus territórios, uma corrida desenfreada entre-nações acarretaria segundo boa parte da doutrina a erosão de bases fiscais de per si. Cf. Carbajo Vasco (2015, p. 61).

75 Cf. Carbajo Vasco (2015, p. 61).

76 Cf. Carbajo Vasco (2015, p. 61).

77 Cf. Straffin (1993, p. 3 et seq.).

78 Cf. Varian (1992, p. 410 et seq.).

79 O ótimo de Pareto, cujo nome advém da obra do economista italiano Vilfredo Pareto, insere-se na análise lógica de situações de conflito e cooperação. Dentro da teoria dos jogos, um ótimo de Pareto constitui uma combinação de estratégias tal que não admite outra situação em que pelo menos um agente seja beneficiado sem que nenhum outro fique prejudicado. Trata-se da maximização da eficiência social, relevante para o espectro de agentes envolvidos como um todo coletivo.

80 V.g., dois agentes comungando ações e interesses, parcial ou totalmente.

${ }^{81}$ V.g., dois agentes em oposição de ações e interesses.
} 
conflito de interesses, ${ }^{82}$ de particular interesse portanto ao espectro de estudo das ciências jurídicas e econômica (esta por lidar com o fenômeno da escassez, aquela por voltarse à máxima suum cuique tribuere, ou "dar a cada um o que é seu” em face de lides concretas). $\mathrm{Na}$ intersecção de ambas, uma solução ao problema de tax shelters perpassaria obrigatoriamente, em um primeiro plano, a compatibilização das normas de legislações domésticas entre si, e em um segundo patamar - ainda utópico no estágio atual evolutivo do Direito Tributário Internacional - sua universalização.

Cotejada a dinâmica tributária internacional à teoria dos jogos, ${ }^{83}$ depreendese que a atual [falta de] cooperação no cenário globalizado traz em seu bojo problema muito assemelhado ao "Dilema do Prisioneiro". ${ }^{84}$ Individualmente, cada um dos "players" (os países) orienta-se à maximização de seu bem-estar nacional, flexionando sua política tributária doméstica à maximização da arrecadação ${ }^{85}$ nacional. $\mathrm{Na}$ esfera coletiva, porém, nem sempre há consenso quanto ao melhor modus de concerto tributário.

Como aponta a revisão de literatura estrangeira, ${ }^{86}$ um primeiro passo na política tributária internacional seria perguntar-se se o foco deveria ser o bem-estar

82 O exemplo mais paradigmático da theory of games está no "Dilema do Prisioneiro". Trata-se do leading case em ciências sociais para ilustrar como a racionalização extrema da lógica egoístico-individual pode conduzir a resultados coletivos não Pareto eficientes. Nele, dois prisioneiros ( " $A$ " e " $B$ ") são detidos pela Polícia e interrogados em salas separadas, sem que um conheça o teor do interrogatório do outro. Cada qual deles poderá adotar duas estratégias: “denunciar” ou "não denunciar” seu comparsa, e são-lhes explicadas as consequências de cada uma dessas decisões possíveis. Assim, se ambos ( " $A$ " + " $B$ ”) denunciam, os dois serão condenados a 6 (seis) anos de prisão cada qual; se nenhum denuncia ("não $A$ " + "não B"), os dois serão condenados a 3 (três) anos de prisão cada qual, por um delito de menor gravidade; já se apenas um deles denunciar ( “ $A$ " + não $B$ ”, ou “não $A$ " + “ $B$ ”), o denunciante será preso por apenas 1 (um) ano, mas o comparsa denunciado será condenado a 9 (nove) anos de reclusão. Analisando as estratégias possíveis a cada jogador, verifica-se nítida tendência a proceder egoisticamente (dado que assim obtém-se pela lógica individual a maximização de eficácia quanto ao resultado: se A denunciou, então a B será preferível "denunciar" em relação à conduta "não denunciar", pois receberá assim 6 (seis) anos de prisão em vez de 9 (nove); se A não denunciou, então a B continuará preferível “denunciar” em relação à conduta “não denunciar", pois receberá 1 (um) ano de prisão em vez de 3 (três). Em ambos os casos, “denunciar” gera sempre um resultado egoisticamente mais eficiente a quem precisa tomar a decisão. Sob o ponto de vista coletivo, porém, a solução ótima seria aquela que levaria ao menor número de anos de cadeia, considerados todos os participantes: trata-se justamente da solução "não denunciar + não denunciar", situada fora da curva ótima-individual”. Para ela, há um número total de $3+3=6$ anos de cadeia. Já para qualquer solução situada na curva ótima-individual ( $A$ " + não $B$ ", ou "não $A$ " + "B"), temos $1+9=10$ anos de cadeia. A teoria dos jogos expõe destarte como a "melhor solução individual” nem sempre será Pareto eficiente. Cf. Ferreira e Ferreira (2008).

83 Cf. Straffin (1993, p. 3 et seq.)

84 Cf. Straffin (1993).

85 Tal coincidência é por nós tomada como premissa conceitual à exequibilidade da análise. Dado que o valor "maximização de bem-estar" é intrinsicamente subjetivo e afeto a valores intangíveis, fazemo-lo equivaler à "maximização da arrecadação nacional”. A subsunção é tomada como lógica necessária: o acréscimo à base tributária e às receitas nacionais permitiriam investir nas atividades geradoras do incremento de bemestar almejado, seja ele qual fosse, e por mais variado pudesse ser a cada jurisdição em específico.

${ }^{86}$ Cf. Shaviro (2009a); Shaviro (2000); Shaviro (2007); Shaviro (2011); Shaviro (2009b) e Seida; Wempe (2004). 
econômico nacional, ou se ao revés, o bem-estar econômico mundial. Esta perspectiva normativa subjacente seria crucial à própria continuidade do debate, e ainda mais relevante quando considerada a temática da tributação de capitais alocados offshore.

No cenário doméstico, a razão primacial em favorecer políticas de neutralidade fiscal está em que a tributação, embora “custo” ao contribuinte, refletiria uma "transferência social" relevante, ao permitir ao Tesouro satisfazer demandas de outros concidadãos. O mesmo raciocínio não se sustentaria no estudo da tributação internacional, a menos que contabilizássemos como benefícios os reflexos gerados a cidadãos residentes em outros países e jurisdições. ${ }^{87}$

Sob ponto de vista estritamente ético, caso firmemos - como premissa axiológica - que todos os seres humanos são dotados de valor em si mesmo, ${ }^{88}$ e que todos possuem o mesmo valor uns comparados aos outros, ${ }^{89}$ o foco no bem-estar global (transnacional) seria autoevidente e despiciendo. Não é o que fazem as nações na prática, porém, e muito menos os próprios indivíduos no tratamento dispensado a seus pares nacionais. ${ }^{90}$

Ora, se o interesse próprio é - dentro de certos limites - aceitável em práticas egoísticas individuais, tanto mais o seria nas condutas de nações soberanas, e a casuística demonstra - tal como nos fluxos migratórios hodiernos do triênio 2016-20172018 - que o favorecimento de objetivos predominantemente altruísticos traz em seu bojo ainda acirradas controvérsias dos eleitorados nacionais. ${ }^{91}$

87 Cf. Shaviro (2009a).

88 O conceito jusfilosófico de "valor em si mesmo" remete ao imperativo categórico kantiano, explicitado na Crítica da Razão Pura. Kant constrói a regra de ouro da filosofia moral ao predizer "[a]ge de tal modo que a máxima de tua vontade possa valer-se sempre como princípio de uma legislação universal", na prática reformulada como "não faças aos outros o que não quiseres que aconteça a ti". Ao centrar o fundamento e ratio essendi da ética na racionalidade humana, o filósofo atribui um valor axiológico imanente a cada ser humano, senhor de si e no tratamento com seus pares. Em termos simples, cada ser humano é visto "como fim em si mesmo", nunca como "meio à consecução de dado fim". Cf. Kant (1959, p. 64).

89 A "igualdade de valor" é um corolário jusfilosófico da premissa kantiana: se todos são tratados como fim em si mesmos, é porque todos são dotados de valor; a contrario senso, como nenhum ser humano jamais poderá ser - por imperativo moral - “coisificado” em sua essência, todos são equiparados ontologicamente, remanescendo todos em situação de igualdade uns em correlação aos outros. Cf. Kant (1959).

90 O Professor Daniel Shaviro refere-se a exemplo prático concreto: ele mesmo, enquanto Professor e autor de análises tributárias e econômicas distributivas sob ótica utilitarista, enfatiza a utilidade marginal decrescente do capital, mas nem por isso entrega de imediato todo seu "dinheiro excedente" aos pobres. Uma tal atitude mostrar-se-ia louvável e/ou benemerente, mas dentro de certos limites a moralidade comum aceita (e incentiva) certos graus de egoísmo individual (e social). Cf. Shaviro (2009a, p. 77).

91 Veja-se, por exemplo, os fluxos migratórios intraeuropeus e as reações do eleitorado alemão diante da política, verbis: "Desafios. Desde que a crise de migração e refúgio atingiu o auge, em meados de 2015, a primeira-ministra, Angela Merkel, sofreu bastante pressão dentro da própria coalizão de governo diante das políticas de abertura para refugiados". Cf. Moraes (2016); Dias (2016) e Doncel; Otero (2016). 
Aos defensores do paradigma de bem-estar universal, ${ }^{92}$ um tal debate de política tributária internacional seria na verdade erroneamente polarizado, à medida que em consonância com a cooperação concertada da teoria dos jogos - o favorecimento de cidadãos de outras jurisdições seria em igual medida uma política ótima ao favorecimento da própria macroeconomia doméstica nacional, no longo prazo. ${ }^{93}$

$\mathrm{O}$ argumento de ouro, neste ínterim, estaria em que políticas nacionalistas de curto prazo minariam o bem-estar econômico global, ${ }^{4}$ porquanto outros países replicariam-nas em efeito cascata; dentro deste debate, o foco real da disputa não seria tanto um embate "bem-estar nacional vs. bem-estar universal", mas antes por qual maneira perseguir a política ótima ${ }^{95}$ de consecução do próprio bem-estar nacional. ${ }^{96}$

Ao que tudo indica, os atuais ajustes plurilaterais da comunidade internacional - firmados nas últimas políticas BEPS - sinalizam uma gradativa compreensão (e adoção) de medidas ao mesmo tempo egoístas e altruístas: os países parecem paulatinamente perceber que a proteção à erosão de bases tributárias nacionais depende do concerto em rede e sistêmico de interesses pluridimensionais, encetando contatos e esforços comuns de jurisdições plúrimas, ${ }^{97}$ ainda que isto implique - no curto prazo - a renúncia parcial de dadas condições ou posições até então vigentes. ${ }^{98}$

É neste quadro e conceito que (re-)inserimos a proposta de tratamento interdisciplinar dos fenômenos econômico e jurídico, esperando que possa servir de simples ponto de partida ao debate profuso da academia, e a latere, à internalização de propostas racionais que contribuam ao desiderato de progresso de países e sociedades como um todo.

São Paulo, 5 de dezembro de 2019.

92 Cf. Shaviro (2009a, p. 77).

93 Isto explicaria, por exemplo, por que proponentes desta política dita de "bem-estar global" simplesmente não advogam a doação unilateral (e integral) de recursos de nações mais ricas às mais pobres; ao revés, a adoção de políticas de cooperação internacional seria benéfica - por óbvio às nações diretamente favorecidas - mas também àquelas que hoje estariam no curto prazo "no contrapolo", na condição de nações ricas e ajudantes.

94 Novamente, a racionalização exponencial de uma lógica egoístico-individual poderia conduzir a resultados coletivos não Pareto eficientes. Cf. Ferreira; Ferreira (2008).

95 Cf. Shaviro (2009a, p. 77).

96 Cf. Friedman (2006, p. 504).

97 Cf. García Novoa (2003, p. 40-44).

98 A título de exemplo, destacamos que o número de jurisdições dotadas de regras " $C F C$ ", nesse ínterim, sofreu acréscimos significativos nas últimas quatro décadas. 


\section{Referências}

AVI-YONAH, Reuven Shlomo. Globalization, tax competition and the fiscal crisis of the welfare state. Harvard Law Review, Cambridge, MA, v. 113, n. 7, p. 1.573-1.676, May 2000.

BANKMAN, Joseph; GRIFFITH, Thomas. Social welfare and the rate structure: a new look at progressive taxation. California Law Review, Berkeley, v. 75, n. 6, p. 1.905-1.967, Dec. 1987.

BOBBIO, Norberto. A função promocional do direito. In: BOBBIO, Norberto. Da estrutura à função: novos estudos de teoria do direito. Tradução de Daniela Beccaccia Versiani. Barueri: Manole, 2007.

BOBBIO, Norberto. Contribución a la teoría del derecho. Valência: Fernando Torres, 1980. (Colección El derecho y el estado).

CARBAJO VASCO, Domingo. El plan de acción de la iniciativa BEPS. Una perspectiva empresarial. Crónica tributaria, Madrid, n. 154, p. 49-67, 2015.

CARVALHO, Paulo de Barros. Curso de direito tributário. 19. ed. São Paulo: Saraiva, 2007.

COASE, Ronald Henry. The nature of the firm. Economica, Hoboken, v. 4, n. 16, p. 386-405, Nov. 1937.

CONESA, Juan Carlos; KITAO, Sagiri; KRUEGER, Dirk. Taxing capital? Not a bad idea after all! American Economic Review, Pittsburgh, v. 99, n. 1, p. 25-48, Mar. 2009.

DIAS, Joana de Sousa. "Os alemães não querem que $60 \%$ da população seja muçulmana". Diário de Notícias, Lisboa, 8 maio 2016. Disponível em: https:/www.dn.pt/mundo/interior/os-alemaes-naoquerem-que-60-da-populacao-seja-muculmana-5163062.html. Acesso em: 15 nov. 2017.

DONCEL, Luis; OTERO, Lara. Alemanha e Suécia aceleram a expulsão de imigrantes. El País, Madrid, 30 jan. 2016. Disponível em: https://brasil.elpais.com/brasil/2016/01/28/ internacional/1453969259_416765.html. Acesso em: 15 nov. 2017.

FERREIRA, Fernanda A.; FERREIRA, Flávio. Equilíbrio de Nash versus Óptimo de Pareto: racionalidade individualista versus racionalidade altruísta. Escola Superior de Estudos Industriais e de Gestão, Instituto Politécnico do Porto, Porto, p. 7-10, ago. 2008. Disponível em: https://recipp. ipp.pt/bitstream/10400.22/7283/1/ART_FernandaAFerreira_2008_1.pdf.

FRIEDMAN, Thomas Loren. Thank you for being late: an optimist's guide to thriving in the age of accelerations. New York: Farrar, Straus and Giroux, 2006.

GARCÍA NOVOA, César. Reflexiones sobre la influencia de la globalización en los principios tributarios. In: TÔRRES, Heleno Taveira (coord.). Direito tributário internacional aplicado. São Paulo: Quartier Latin, 2003.

GEEST, Gerrit De. The debate on the scientific status of law \& economics. European Economic Review, Amsterdam, NY, v. 40, n. 3-5, p. 999-1.006, abr. 1996. 
GROVES, Harold Martin. Tax philosophers: two hundred years of thought in Great Britain and the United States. Madison: University of Wisconsin Press, 1974.

HANSMANN, Henry. The current state of law-and-economics scholarship. Journal of Legal Education, Durham, CN, v. 33, n. 2, p. 217-236, June 1983.

HINES, James R. Three sides of Harberger triangles. Journal of Economic perspectives, Nashville, v. 13 , n. 2, p. 167-188, 1999.

KANT, Immanuel. Crítica da razão prática. Tradução e prefácio Afonso Bertagnoli. São Paulo: Brasil Editora S.A., 1959.

KAPLOW, Louis. How tax complexity and enforcement affect the equity and efficiency of the income tax. National Tax Journal, Lancaster, v. 49, n. 1, p. 135-150, Mar. 1996.

KIRAT, Thierry. Économie du droit. Paris: La Découverte, 2012. (Collection Repères).

KOPCZUK, Wojciech. Tax simplification and tax compliance: an economic perspective. In: SAWICKY, Max B. (ed.). Bridging the tax gap: addressing the crisis in federal tax administration. Washington, DC: Economic Policy Institute, 2005.

KRUGMAN, Paul; WELLS, Robin. Introdução à economia. Tradução Helga Hoffmann. Rio de Janeiro: Elsevier, 2007.

KRUGMAN, Paul; WELLS, Robin. Microeconomia: uma abordagem moderna. Tradução Regina Célia Simille de Macedo. 3. ed. Rio de Janeiro: Elsevier, 2015.

LAFFER, Arthur B. The Laffer curve: past, present, and future. Backgrounder, Washington, DC, n. 1.765, 1 June 2004. Disponível em: http://s3.amazonaws.com/thf_media/2004/pdf/bg1765.pdf.

MANKIW, Nicholas Gregory; WEINZIERL, Matthew Charles; YAGAN, Danny Ferris. Optimal taxation in theory and practice. Journal of Economic Perspectives, Nashville, v. 23, n. 4, p. 147-174, jan./dez. 2009.

MIRRLEES, James A. An exploration in the theory of optimum income taxation. The Review of Economic Studies, London, v. 38, n. 2, p. 175-208, Apr. 1971.

MORAES, Aline. Alemanha cria primeira lei para integração de migrantes e refugiados. Agência Brasil, Brasília, DF, 14 abr. 2016. Disponível em: http://agenciabrasil.ebc.com.br/internacional/ noticia/2016-04/alemanha-cria-primeira-lei-para-integracao-de-migrantes-e-refugiados. Acesso em: 15 nov. 2017.

O’REILLY, Terrance. Economics \& economic substance. Florida Tax Review, Gainesville, v. 9, n. 9, p. 755-792, 2010.

O'REILLY, Terrance. Principles of efficient tax law: apocrypha. Virginia Tax Review, Charlottesville, v. 27. n. p. 583-630, 2008. Disponível em: https://papers.ssrn.com/sol3/papers.cfmabstract id=1017186. Acesso em: 15 nov. 2017. 
PIGOU, Arthur Cecil. The economics of welfare. 4. ed. London: MacMillan \& Co. Publishers, 1932. POSNER, Richard A. Economic analysis of law. 6. ed. New York: Aspen Publishers, 2003.

POSNER, Richard A. Values and consequences: an introduction to economic analysis of law. Law \& Economics Working Papers, Chicago, No. 53, 1988. Disponível em: https://chicagounbound. uchicago.edu/cgi/viewcontent.cgi?article=1607\&context=law_and_economics.

RASKOLNIKOV, Alex. Accepting the limits of tax law and economics. Cornell Law Review, Ithaca, v. 98, n. 3, p. 523-590, Mar. 2013. Disponível em: https://www.lawschool.cornell.edu/research/ cornell-law-review/upload/Raskolnikov-final.pdf.

REALE, Miguel. Filosofia do direito. 20. ed. São Paulo: Saraiva, 2002.

SALAMA, Bruno Meyerhof. O que é pesquisa em direito e economia? Cadernos Direito GV, São Paulo, v. 5, n. 2, mar. 2008.

SEIDA, Jim A.; WEMPE, William F. Effective tax rate changes and earnings stripping following corporate inversion. National Tax Journal, Washington, DC, v. 57, n. 4, p. 805-828, out./dez. 2004.

SHAVIRO, Daniel N. Decoding the U.S. corporate tax. Lanham: Rowman \& Littlefield, 2009.

SHAVIRO, Daniel N. Economic substance, corporate tax shelters, and the Compaq case. Tax Notes, Arlington, v. 88, n. 2, p. 221-244, July 2000.

SHAVIRO, Daniel N. In defense of requiring back-flips. Virginia Tax Review, Charlottesville, v. 26, Jan./Dec. 2007.

SHAVIRO, Daniel N. The case against foreign tax credits. Journal of Legal Analysis, Oxford, v. 3, n. 1, p. 65-100, Mar. 2011.

SHAVIRO, Daniel N. The Obama administration's tax reform proposals concerning controlled foreign corporations. London: Sweet \& Maxwell, 2009. p. 331-339. (British Tax Review, v. 4).

SILVA, Brenno Birckholz da. Le point optimal de la fiscalité internationale et son impact économique dans l'internationalisation productive: une étude du rapport coût-bénéfice fiscal sous la perspective des régimes brésilien et français. 2020. Tese (Doutorado) - Cotutela entre a Université de Bordeaux e a Universidade de São Paulo, São Paulo, 2020.

SLEMROD, Joel. Optimal taxation and optimal tax systems. Journal of Economic Perspectives, Nashville, v. 4, n. 1, p. 157-178, July/Sept. 1990.

SLEMROD, Joel. The economics of corporate tax selfishness. National Tax Journal, Washington, DC, v. 57, n. 4, p. 877-899, Oct./Dec. 2004.

STRAFFIN, Philip D. Game theory and strategy. Providence: American Mathematical Society, 1993. (New Mathematical Library, No. 36).

SUGIN, Linda, A philosophical objection to the optimal tax model. Tax Law Review, New York, NY, v. 64, n. 2, p. 229-281, May 2011. 
ULEN, Thomas S. A Nobel Prize in legal science: theory, empirical work, and the scientific method in the study of law. University of Illinois Law Review, Chicago, v. 2002, n. 4, p. 875-920, Jun. 2003. VARIAN, Hal R. Microeconomic analysis. 3. ed. New York: W. W. Norton \& Company, 1992.

WEISBACH, David. A. Ten truths about tax shelters. Tax Law Review, New York, v. 55, n. 2, p. 215-253, 2002. 